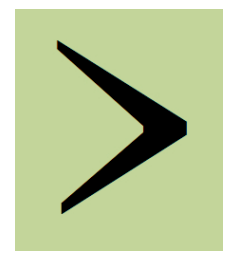

\author{
Papers in Historical Phonology \\ http://journals.ed.ac.uk/pihph \\ ISSN 2399-6714 \\ Volume $1,5-36$ \\ DOI : $10.2218 /$ pihph.1.2016.1691
}

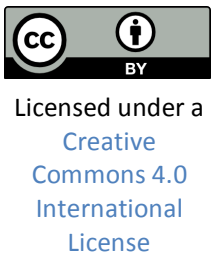

\title{
Examining the life cycle of phonological processes: considerations for historical research
}

\author{
RANJAN SEN \\ University of Sheffield
}

\begin{abstract}
The life cycle of phonological processes (e.g. Bermúdez-Otero 2015) provides an account of how a sound change might develop over the history of a language, from its beginnings in the pressures of speaking and hearing, through its progress to a cognitively-controlled process and maturation into a categorical phenomenon, to its final resting-place as a lexical or morphological pattern. It has been the subject of increased research in recent times, but has faced strikingly few challenges to its diachronic aspects, notably its predictions of unidirectionality and cyclebased dialectal splits. Furthermore, the cognitive mechanisms rooted in morpheme-based learning which are required to predict domain narrowing (phrase $>$ word $>$ stem) rather than broadening need to be tested through child (and adult) acquisition studies. This paper examines how a historical phonologist might go about interrogating the life-cycle model using extensive historical data spanning several centuries, and methodically ascertaining what the model predicts in order to know what to look for. The paper concludes by briefly addressing some of the many other questions raised by the model which have faced comparatively little investigation given the purported pervasiveness of the life cycle.
\end{abstract}

\section{The life-cycle model}

The life cycle of phonological processes (e.g. Bermúdez-Otero 2015) provides an account of how a sound change might develop over the history of a language, from its beginnings in the pressures of speaking and hearing, through its progress to a cognitively-controlled process and maturation into a categorical phenomenon, to its final resting-place as a static lexical or morphological pattern. It has been the subject of increased research in recent times, particularly in the work of Bermúdez-Otero under the rubric of Stratal Optimality Theory (OT); this theory of phonology relates synchronic grammar (phonology and morphology) to diachronic development, in a way that has proven 
fruitful for accounting for synchronic opacity, one of the major challenges to traditional OT. Consequently, Stratal OT has been contested by proponents of theories which deal with opaque interactions in synchronic phonology in other ways, and morphological theories which argue for the separation into a separate linguistic module of morphological patterns. However, Stratal OT has faced strikingly few challenges to its diachronic aspects, notably its notion of a strictly defined life cycle. I refer here to the diachronic aspects of this theory as 'the life-cycle model' (LCM).

Phonological processes start from language-independent, universal phonetic effects, becoming cognitively-controlled, language-specific phonetic implementation regularities (phonologization). They then become stabilized as categorical (synchronic) processes manipulating phonological units in linguistic computation; this occurs first in the context of full utterances, the phrase level (PL), then over time may come to affect word domains regardless of surrounding lexical context, the word level (WL), before applying within morphological stems regardless of surrounding morphological context (e.g. word-forming prefixes and suffixes), the stem level (SL). This gradual diminution in the domain of application of a process (domain narrowing) reflects the increasing sensitivity of a synchronic process to morphosyntax, absent from earlier historical stages of the sound change. Finally, the process might cease to be a dynamic aspect of linguistic computation; its surface effects are deemed to be intrinsic properties of lexical items (lexicalization), that is, the post-sound change form of the word is the stored version, not derived by online processing. Alternatively, the effect might be bound up with a morphological operation alone, and again no longer be a part of phonological computation (morphologization).

Whereas the synchronic consequences of several computational strata have been explored and debated (e.g. McCarthy 2002, Vaux 2008), as noted above the diachronic predictions of the LCM and its purported cognitive mechanisms have not been examined in much depth. There are numerous indications, reported over the last few decades, that the stages of the LCM appear in strict order in sound changes across several languages. However, despite the identification of this fascinating pattern, alarmingly little research has explored the pervasiveness of the life cycle, and interrogated the full range of predictions of the LCM, such as the regularity of unidirectionality (that is, domain narrowing not broadening). Its proponents claim that "It should be as inconceivable for phonetic, phonological, and morphological research to proceed in ignorance of this life cycle as it is for research into morphology, syntax, semantics, and pragmatics to 
ignore the facts of grammaticalization" (Bermúdez-Otero and Trousdale 2012), while acknowledging that the life cycle is not absolutely, but rather "largely unidirectional" (2012).

The attribute of unidirectionality has received some attention in the literature, as have the related notions of modularity - each stage transforms an input into an output through level-specific information and the restriction of gradience in phonological processes to stages prior to stabilization, i.e. the phonetic implementation module. Studies such as Bermúdez-Otero \& Trousdale (2012) and Ramsammy (2015) address some challenges to these three properties, invoking devices such as rule-scattering (versions of the same rule simultaneously at different levels) to explain effects which should not occur according to a naïve version of the model. ${ }^{1}$ These studies demonstrate the potential of the LCM in improving the understanding of diachronic phenomena, but remain relatively isolated; the life cycle remains one of the most curious, yet comparatively understudied, patterns in sound change. In particular, there has been little attempt to examine historical data systematically to discover challenges to the model, or interrogate every aspect of the LCM to ascertain its diachronic predictions. This paper examines how these gaps may be addressed.

Bermúdez-Otero \& Trousdale (2012) illustrate the LCM with reference to /g/-deletion in English /.gg/. In early modern English, the final / $\mathrm{g} /$ appears to have been pronounced in every position, even at the ends of sentences, hence sing $=$ [sing]. At a later stage, we have evidence that $/ \mathrm{ng} /$ was pronounced at the end of a word only if the next began with a vowel, hence in sing it $=$ [singit], but $/ \mathrm{g} /$ was deleted if it was before a consonant or at the end of a sentence, hence [sin]. From a phonetic standpoint, deletion is an easily explicable phenomenon: at the end of a sentence or before a consonant in connected speech, a final /g/ after another consonant (/g/) might be poorly cued, so a new generation of speakers may simply choose not to expend great effort in producing it in this position. When this occurs, the languageindependent physical phonetic effect has come under cognitive control (expend less effort for final /g/), with gradient results in implementation, i.e. it has been phonologized. Subsequently, this effect became categorical when stabilized: instead of reducing the effort expended to produce $/ \mathrm{g} /$, speakers opted to expend none at all, i.e. they deleted it utterance-finally and pre-consonantally. At this stage, deletion was a phrase-level process whose positions were determined by its phonetic precursors. Later in time, we have evidence from the

1 I use the term "rule" informally throughout this paper to refer to phonological computation. 
eighteenth century that $/ \mathrm{g} /$ was deleted at the end of a word regardless of the initial sound of the following word, hence sing it $=$ [sinit], in addition to the environments where it was already deleted. However, the /g/ was still pronounced word-internally before a vowel-initial suffix, hence sing-er $=$ [singə]. At this stage, deletion was a word-level process, with the instruction "delete final /g/" looking at word domains. Finally, in Present-Day English, /g/ is deleted even in this last context: [sinə]; the only morphosyntactic context in which /ng/ remains is morpheme-internally, e.g. elongate. Deletion is therefore a stem-level process, looking for the environment "final" within stem domains. Note furthermore that every instance of the morpheme sing would now undergo /g/-deletion (as it is always final in the stem); this has presumably lead to the lexicalization of the morpheme in some speakers without that final /g/, i.e. /sin/.

The sound change therefore became increasingly sensitive to its position within sentences and words, with otherwise identical phonological environments. The rule was still one of deletion preconsonantally and "finally". Why did /g/-deletion behave in this way, especially when a following vowel could provide robust phonetic conditions for the perception of $/ \mathrm{g} /$ ? The LCM appeals to input restructuring based on the frequency of morpheme alternants: while /g/-deletion was a phrase-level process, the final/pre-consonantal alternant [sIn] surfaced three times more frequently than the prevocalic alternant [sing], leading learners to generalize the token-based pattern and reanalyse the input to the phrase level as /sin/; at this point /g/-deletion became a word-level process, as the /g/-less form was the output of the word level (Bermúdez-Otero and Trousdale 2012). Successive rounds of input restructuring led to further domain narrowing to the stem level, following by item-specific lexicalization.

Historical studies too often concentrate on (much-needed, valuable) descriptive presentations of phenomena and their contexts, regularly through impressive detailed investigation, but to the detriment of explanatory theoretical considerations. In stark contrast, synchronic phonology regularly lays great emphasis on theory, rigorously establishing and testing predictions of scientific models, but concentrating on synchronic patterns often in an anti-historical vacuum, or occasionally invoking diachronic evidence without sufficient consideration of its status in synchronic explanation. This dichotomy is understandable given the interest of historical linguists commonly on language-specific phenomena, and synchronic linguists on language-universal structures. Recent attempts to formalize sound change theory, such as Blevins' (2004) Evolutionary Phonology, make some progress in explaining the actuation of change, but several 
patterns seen in the history of changes remain untouched, such as the life cycle. It might be fruitful to explore how far we can hold theories of diachronic phonology up to the same standards of scientific rigour as synchronic linguistic theories, methodically ascertaining testable predictions of core hypotheses, and accumulating appropriate data from historical phenomena to allow those tests to be implemented. The full explanation of the history of a sound change must not merely be a formalized restatement of a pattern, but a testable analysis.

\section{Challenges to the LCM}

The life-cycle model presents numerous unaddressed questions. Three core predictions at the heart of the diachronic claims of the LCM are:

(1) Unidirectionality

Yesterday's (X)-level phonology is today's (X-1)-level phonology

I.e. phrase > word > stem; domain narrowing not broadening

(2) Dialect continua

Dialectal variation might be expected to reflect different stages in the life cycle

E.g. the same change may only have reached the word level in a conservative dialect, but the stem level in an innovative one

(3) Morpheme-based learning

Learners will interpret data in ways which will result in either domain narrowing or no change to a domain of application, based on morpheme alternations

I.e. language-learning biases, e.g. in infants, cause unidirectionality

As noted in $\S 1$, "unidirectionality" is an expected outcome given the morphosyntactic basis of the LCM: domain narrowing results from gradually increasing structural analysis of the input in relation to the operation of the process, which concomitantly travels further from its phonetic roots. We should therefore not find, in the normal course of language development, a process which comes to apply in a larger domain from a smaller. The second of these, "dialect continua", acknowledges the linguistic reality that languages are not homogeneous entities that change in a uniform fashion, but are the products of communities of practice (e.g. Eckert and McConnell-Ginet 1992). If communities speaking a language differ in the generalizations adopted by a new generation, a life-cycle-based dialect split is predicted to occur and be visible in the historical record even if no longer present. These 
challenging predictions must be tested by reliably detailed, long-term, cross-linguistic diachronic data in a manner that is hitherto absent.

The last of these, "morpheme-based learning", is a necessary prerequisite for domain narrowing. We should be able to replicate in the laboratory the cognitive mechanisms underlying unidirectionality, notably morpheme-based analysis, generalizing patterns in order to reduce alternation. What we should not find is a preference for gross phonotactic generalizations over morpheme-based learning. For example, if $75 \%$ of a hypothetical lexical input /pad/ gave the phraselevel output [pat], with the other $25 \%$ giving faithful [pad], a learner might treat a word-level output to be /pat/, generalizing the majority pattern as the input to the phrase level. If there was sufficient evidence across morphemes of devoiced alternants bearing this kind of 75:25 distribution, we would expect domain narrowing of the devoicing rule from PL to WL. However, given a second hypothetical language with no relevant alternation, but $75 \%$ of word-final plosives voiceless and $25 \%$ voiced, we should not expect learners to devoice all word-final plosives simply because the majority of final plosives happened to be voiceless. As discussed in $\S 5$, this latter kind of generalization in languagelearning might lead to widespread domain broadening, contrary to the predictions of the LCM.

The three predictions above are at the heart of the LCM: sound changes are increasingly structuralized as they progress because learners can only generalize input in this way, resulting in different communities speaking the same language structuralizing at different rates. The three claims therefore form a cohesive explanatory model of diachronic phonology. However, the model raises several other questions which are closely bound with the predictions above.

(4) Are the phonological levels in synchronic computation innate or acquired (some thoughts in Bermúdez-Otero 2007)?

(5) How are gradient, phonetic instructions computed and implemented in the "phonetic rule" module (some thoughts in Bermúdez-Otero and Trousdale 2012, citing Hamann 2009)?

(6) Is rule-scattering sufficient to account for phonetics apparently sensitive to morphology or the lexicon (Bermúdez-Otero 2015, Ramsammy 2015, but also Sebregts and Strycharczuk 2012; see Turton 2012)?

(7) Are there phonetically gradient, lexically gradual sound changes (e.g. Bybee 2002, Phillips 2015), contrary to the predictions of the life cycle? 
(8) Do lexically diffusing changes reflect lexically varied phonological computation rather than varied lexical storage (see references in previous point)?

(9) What is the full range of predictions of the non-analytic listing of stem-level outputs (Bermúdez-Otero and McMahon 2006) and are these borne out?

(10) What are the factors conditioning the duration of a change's life cycle, and whether it is seen through to lexicalization (some thoughts in Bermúdez-Otero 2015)?

(11) How does domain narrowing interact with different types of rule generalization, either by natural class or by prosodic span, which can extend the application of a rule within a given level (some thoughts in Ramsammy 2015)?

(12) How can the morphosyntactic cycle interact with the computation of prosodic structure in conditioning sound change (e.g. Bermúdez-Otero and Luís 2009, Sen 2015a)?

The sheer number of issues listed, still only a sample, demonstrates the pressing need for the LCM to be fully interrogated. The next three sections in this paper will focus on the issues relating to (1)-(3); questions (4)-(12) will be briefly discussed in $§ 6$, as several are better addressed with a non-diachronic focus, e.g. through phonetic experimentation.

\section{Unidirectionality}

The LCM predicts unidirectional diachronic domain narrowing, which can be broken down into four claims: (a) "yesterday's gradient phonetic effect is today's categorical phrase-level phonology", (b) "yesterday's phrase-level phonology is today's word-level phonology", (c) "yesterday's word-level phonology is today's stem-level phonology", and (d) "yesterday's stem-level phonology is today's lexical form/morphological operation". The primary difficulty that a historical phonologist will face is that a change may not be reflected in spelling or through other phonological indications (e.g. puns, rhymes), at any (or all) of the stages. Catching a given change mid-cycle may therefore be impossible.

The first of these is the most difficult to explore in historical language forms, as gradience is difficult to ascertain when phonetic measurements are impossible. Indeed, Bermúdez-Otero \& Trousdale (2012) note that determining whether a process is gradient or 
categorical "requires careful statistical analysis of high-quality phonetic data from individual speakers" of the type found in Ellis \& Hardcastle (2002) for external sandhi in English /n\#k/. See also Strycharczuk (2012) on pre-sonorant, word-final /s/-voicing in Quito Spanish, where speech rate clarifies whether the process is gradient or categorical in a given speaker. However, some indications of gradience may be recoverable and can be instructive. For example, if a process is gradient at a given point in time, it may (if we are lucky) be reflected in spelling in all affected environments, but much more frequently in the phonetic conditions where the effect is more pronounced. For example, rates of orthographically represented regressive stop place assimilation may be directly correlated with the scalar phonetic properties of the effect, with coronal spellings altered the most and dorsal ones the least (see Jun 2004 on the scale, and Sen $2015 \mathrm{~b}$ for a historical effect). In a similar vein, Sen (2015b) reconstructs gradient, contextually conditioned darkening in early to classical Latin onset /l/, based upon the degree of (orthographically represented) backing of the preceding vowel in different contexts (e.g. inherited /e/ became $<\mathrm{u}>$ before internal /lu lo la/, but $<0>$ before /le:/, and remained unbacked before /li/). Sen (2015b) argues that a categorical analysis such as feature spreading would not predict the complex vowel conditioning pattern discovered. Although this is true of its actuation, the account requires augmentation to consider the later history of the change: after stabilization, the derivation of a back vowel [o] or [u] from a front one may have occurred by categorical rule, even if the origin of the output of that rule was originally conditioned by its phonetic origins. The rule itself would still be categorical and free of phonetic substance. Such patterns may therefore be interpreted as an indication of phonetic gradience at some stage (even if they are stabilized categorical rules which betray their phonetic origins when we encounter them in the historical record), either by their rate of application if optional (assimilation example), or the existence of a set of constituent rules comprising a single process, reflecting the phonetic sensibilities of origins (/l/-darkening example). Ascertaining evidence for synchronic gradience must therefore be done with extreme caution; it is likely it can never be done with complete confidence.

The next stage, the phrase level, will be recoverable for a given change if standard or sub-standard/phonetic spelling in the language reports external sandhi, e.g. Sanskrit standardly, Latin in sub-standard writing. This stage may again be highly susceptible to the challenge highlighted above: phrasal phenomena across word boundaries are often not reported in spelling. We may therefore need to rely on other indications, such as puns and contemporary reports; for example, 
Cicero (Ad. Fam. 9.22.2) ${ }^{2}$ comments on the obscene result of place assimilation in Latin cum nos 'with us' > cunnos 'female genitalia (acc. pl.)'. Bermúdez-Otero \& Trousdale (2012) illustrate the phrase level using two processes in some speakers of English: /n\#k/ external sandhi, and /l/-vocalization. For example, in the sentence See Lynn seal in seal bins, it is only the $/ \mathrm{l} /$ in seal bins (pre-consonantal) that vocalizes, not that in seal in (pre-vocalic). Neither process is represented in standard English orthography, although /l/-vocalization can be recognised in Shakespeare's time through its counterpart, the hypercorrect insertion of word-final /l/, seen in the gravedigger's argal for Latin ergo 'therefore' in Hamlet, Act 5, Scene 1.

The following stage, the word level, has a greater chance of recoverability from the historical record, as spelling often reflects morpheme alternations within words, e.g. Latin agō 'I drive', but āctus 'driven' showing regressive voice assimilation in the stem before the suffix -tus. Alternations resulting from productive morphology therefore give us good evidence of synchronic word-level processes. Bermúdez-Otero (2015) illustrates the word level through post-nasal /g/-deletion in English (with historical evidence from the eighteenthcentury orthoepist James Elphinston), and umlaut in Swiss German (evidence from present-day dialectal variation), both of which rely upon productive morphological operations. Neither process, however, owes much to evidence from historical spelling, and again, other direct and indirect sources such as contemporary reports (e.g. Elphinston, Roman grammarians) on the one hand, and puns, rhymes, etc. on the other would need to supplement available orthographic evidence when interrogating the diachronic predictions of the LCM. Evidence from dialect continua (see §4) may also be instructive, as in Swiss German umlaut.

A key source of evidence for the historical rise of a process to the stem level is analogical levelling whereby a learner reduces alternation in a morpheme. The phonological process can be interpreted as coming to be applied within a stem rather than a word. For example, final devoicing or intervocalic voicing might lead to a stem-final voice alternation depending on whether or not a suffix follows at the word level (hypothetical [pat pad-a] in both processes), but the same stems would be consistently voiceless if only the stem environment is considered in the process (i.e. [pat] = both final and not-intervocalic, so UR /pad/ devoiced to [pat], and UR /pat/ maintained). Domain narrowing to the stem level might be identified in the historical record

2 Abbreviations of Latin authors and works follow the conventions of Glare (ed.) (1996). 
through orthography, given that regular shifts in spelling conventions may occur; for example, in Latin intervocalic rhotacism (e.g. Roberts 2012), stem-initial /s/ remained even when a vowel-final prefix rendered it intervocalic, e.g. dé-siliō 'I jump down' alongside the simplex verb salio 'I jump', indicating that intervocalic $s \rightarrow r$ must be at the stem level. Relics of earlier word-level rhotacism survive in the prefixed ${ }^{*}$ disforms dir-imō 'I take apart' and dir-(h)ibeō 'I lay apart', presumably due to diachronic loss of morphological analysis in these forms, arising from a greater conceptual and phonological distance from their simplices emō 'I take' and habeō 'I hold'.

This latter hypothesis too forms a prediction that needs rigorous investigation: it is clear that etymologically related forms may undergo different phonological histories as they become less transparently connected in the synchronic grammar. Therefore, do originally affixed forms which have become monomorphemic stems systematically show stem-level phonology? Sen (2015b) examines the effect of the loss of morphological transparency on the syllabification of "stop + liquid" (TR) in c. fifth-century BC Latin, concluding, from vowel-reduction evidence, that synchronically transparent TR-initial suffixes were tautosyllabic (tāli-trum 'flick' = /ta:.li.trum/). Conversely, heterosyllabic TR was the (post-short-vowel) treatment for all of (i) synchronically non-transparent TR-initial suffixes (e.g. latebra 'hiding place' < PIE suffix *- $d^{h} r a$ :), (ii) transparently heteromorphemic TR (e.g. any prefix + stem: ab-ripio: 'I abduct'), and (iii) synchronically non-transparent heteromorphemic TR (e.g. cōnsecrāre 'dedicate' < *sak-ro-). Any synchronically opaque TR was therefore heterosyllabic, regardless of its history. This pattern might be analyzed by a stem-level grammar conditioning heterosyllabicity, followed by a word-level tautosyllabic grammar which remained faithful to the syllable structure formed at the stem level. Hence, SL heterosyllabic /la.teb.ra/ and /kon.sak.ra:-/, with the stem /ta:.li-/ for 'flick', followed by WL /la.teb.ra/ and /kon.sek.ra:.re/ (post-vowel reduction), respecting SL heterosyllabicity within the stem, but /ta:li.trum/ with word-level tautosyllabic TR in the transparent suffix. Interestingly, later on in second-century BC Latin (e.g. Plautus), the default syllabification for opaque TR became tautosyllabicity, hence /la.te.bra/. It appears that, in accordance with the life cycle, "yesterday's" WL treatment became "today's" SL level treatment, presumably due to the greater frequency of use of transparent TR suffixes than opaque TR forms (Serbat 1975 discusses all the historically suffixed forms). Implicit in this analysis is that the loss of morphological analysis has potentially profound effects on the life cycle, and its influence on domain narrowing to the stem level in particular. 
Domain narrowing to the stem level might occur if the learner encountered one morpheme alternant (e.g. [pat] in [pat pad-a] above) sufficiently frequently. If the process is intervocalic voicing, ${ }^{3}$ i.e. [[sLpat $\left.{ }_{w L} a\right] \rightarrow$ SF [pada], it now fails to occur in the derived form, i.e. SF [pat-a]. The morpheme /pat/ therefore no longer undergoes alternation, and its lexical representation remains intact. The only place voicing would occur is within stems, i.e. UR /kata/ $\rightarrow$ SF [kada]; as this results in a complete elimination of alternation in stems of such shape (as indeed would a WL or PL process in the absence of opaque rule interactions), the learner of a grammar from such input would presumably assume the simplest hypothesis for this morpheme: the underlying representation of the stem is /kada/. This restructuring of the stored form is the final stage of the life cycle: lexicalization. The voicing rule is no longer required by the learner to derive such SFs, and as we saw above, the rule is now inoperative in stems such as /pat/. Again, the learner may conclude most simply that there is no voicing rule in the grammar. ${ }^{4}$ The failure of voicing at this point in time can be considered to be "rule death".

Conversely, if the [pad] alternant of the morpheme /pat/ was more frequent than [pat] when voicing was a WL rule, the learner may assume that the voiced plosive was in the underlying representation of the morpheme, hence /pad/. This would lead to lexicalization of voicing without an intervening SL rule, given that the intervocalic environment for voicing was not present in the stem in isolation. Again, this is rule death. We may therefore ask under what circumstances a stem-level rule will be manifest in the historical record if both scenarios considered result in rule death and lexicalization. One indication may be precisely where the rule was at the word level before loss of morphological analysis, but the stem level thereafter, as with Latin rhotacism. Therefore at Stage 1, we have WL /dis/ + /emo:/ $\rightarrow$ dirimō 'I take apart'; at Stage 2, the WL input is un-prefixed /disemo:/ without

\footnotetext{
${ }^{3}$ Similar arguments apply if the process under consideration is final devoicing. If the devoiced alternant [pat] is sufficiently more frequent, devoicing may come to apply at the stem level, where SL pad $\rightarrow$ pat; there will no longer be any alternation between [pad] and [pat], resulting in lexicalization of /pat/. If conversely [pad-a] is more frequent, the final devoicing may simply die (UR /pad/ $\rightarrow$ SF [pad]), with nonalternating stems showing WL devoicing becoming lexicalized, e.g. /kad/ becomes /kat/ if this is a stem which does not take vowel-initial suffixes, so has only [kat] alternants.

${ }^{4}$ The situation may be more complex if the learner assumes a redundancy rule at the stem level, as a check on the well-formedness of underlying representations. This would be consistent with the view that stem-level outputs are stored (BermúdezOtero and McMahon 2006).
} 
further analysis of the "stem" element, resulting again in the rhotacized SF through the WL rule. Finally, at Stage 3, the rule rises to the stem level: the new "stem" /disem-/ undergoes SL rhotacism to /direm-/, but /de:/ + /salio:/ with stem-initial /s/ remains unrhotacized dēsiliō 'I jump down'. This reverses the effect of earlier WL rhotacism which would have resulted in unattested ${ }^{\dagger} d \bar{e}$-riliō. It is only the presence of the fossilized forms like dirimō that allows us to reconstruct the WL stage, and the divergent behaviour of stem-internal and stem-peripheral /s/ that allows us to see the SL stage. ${ }^{5}$

Analogical levelling is (again) therefore the clearest historical evidence for the final step of the life cycle, lexicalization. The Latin levelling of honōs, honōris 'honour (nom./gen.)' in Cicero to later honor, -oris is the result of the elimination of stem alternation, with the more frequent $[\mathrm{r}]$-alternant interpreted by the learner as being part of the UR. A naïve LCM would predict that the direction of levelling in each morpheme ought to be based on the token frequency of each alternant alone, but its proponents acknowledge that there may be top-down influences based on overall lexical patterns. For example, we see widespread levelling in favour of the [r]-alternant in Latin, never the [s] (i.e. back to thonōsis) due to the greater frequency of rhotacized oblique forms across all such stems with such $[s \sim r]$ alternations, not simply this one. Nevertheless, the full range of factors conditioning the selection of the base for analogical levelling remains unclear; a fully articulated LCM would therefore need to incorporate a hitherto elusive comprehensive model of analogy. ${ }^{6}$ Furthermore, the circumstances under which a rule may be morphologized rather than lexicalized, or give rise to stored allomorphs of a stem (i.e. several URs) would also need a complete treatment. For example, it is clear that the nominal $-\bar{o} s,-\bar{o} r i s$ pattern remained robust in Latin as it was retained in monosyllables, e.g. mōs, mōris 'custom'. Given that rhotacism ceased to affect new intervocalic /s/ from loanwords (e.g. basis 'pedestal') or the degemination of /ss/

\footnotetext{
5 These data may in theory be interpreted without a SL rule, but chronological considerations indicate otherwise. If dirimō lost all its synchronic connections with /dis/ + /emo:/ while rhotacism was a WL rule, it may simply have been lexicalized as a non-alternating stem /dirim-/, the learner having no evidence for an underlying /s/ from the regular output. At the same time, rhotacism could have simply "died" in alternating forms, with either one alternant or the other lexicalized, e.g. the [s] alternant in dé-siliō. However, this would leave unexplained why alternations such as honōs (nom.), honōr-is (gen.) 'honour' persisted until well into the classical period (Cicero), before honor later became the nominative form of the stem too. While Latin had honōs, dè-siliō and dirimō, it had a stem-level rhotacism rule, targeting steminternal, but not peripheral, intervocalic /s/.

${ }^{6}$ I thank Ricardo Bermúdez-Otero for discussion on this point.
} 
(e.g. caus(s)a 'cause'), it must have ceased to be a synchronic rule of Latin from the classical period. The ongoing monosyllabic treatment must therefore be analyzed as stem allomorphy, with selection of the /s/ or /r/ allomorph based on a robust paradigmatic pattern. Supporting this view, some speakers of Latin appeared to generalize this pattern beyond its original purview, giving nominative iānitōs 'doorkeeper' (beside the usual gen. iānitōris) in place of etymological -tor (Baldi 1994).

Investigating each stage through the examination of historical evidence therefore makes several demands of the data in an ideal research setting.

(13) Historical data required to interrogate unidirectionality in the LCM (in an ideal world)

a. Chronology: several centuries, encompassing indications of the start, middle, and end of several phenomena within a single language

b. Orthography: representing sound change as early in the cycle as possible, e.g. external sandhi for phrase-level changes

c. Direct evidence: statements from grammarians, orthoepists, etc.

d. Indirect evidence: from rhymes, puns, verse scansion, etc.

e. Morphology: affixing languages; diachronic loss of morphological analysis in some formations

f. Phenomena: several processes interacting in the same phonological system

g. Variation: orthographic (and other) variation to indicate the likelihood of the application of a change at a given level

Good possibilities for meeting many of these demands include Latin-Romance, from reconstructed Proto-Latin through to its split into the Romance languages, and English, examining morphosyntactically sensitive changes from its Germanic roots through Old, early/late Middle, and early/late Modern English, to Present-Day English. For example, the phonological development of archaic Latin from its earliest attestations in the c. 7th-century BC through to the present-day Romance languages furnishes us with an attractive testing-ground since (i) reconstructed and attested pre-change forms are mostly uncontroversial because of detailed scholarship in Indo-European and Romance etymology, (ii) there is copious written evidence (orthographic and other direct types, as well as many indirect types) 
over many centuries for the phonological development of the languages, (iii) several changes apparently sensitive to morphosyntactic structure occurred (e.g. consonantal assimilations, /l/-darkening and vocalization, /s+C/-syllabification strategies), and (iv) we can confidently reconstruct successive synchronic systems. Having information to allow us to reconstruct over two thousand years of Latin-Romance enables to test the above predictions rigorously.

Sen (2015a) provides an example of a reconstructed life cycle within the (early) history of Latin, analyzing (in Stratal OT) the stages of "iambic shortening", a phenomenon itself with a long history in the phonological literature (e.g. Mester 1994, Lahiri, Riad and Jacobs 1999, Jacobs 2003, Prince and Smolensky 2004). Certain sequences of "light syllable + heavy syllable" were treated as "light + light" in early Latin, e.g. amō $\rightarrow$ amo 'I love'. This process originally occurred across word boundaries (as well as word-initially and finally), usually with a wordinitial closed syllable being treated as light (denoted below by the breve); this is common in the early Latin verse comedies of Plautus (3rd-2nd centuries BC), e.g. et abdūcere $\rightarrow$ [e.tăb.du..ke.re] 'and to carry off' (Pl. Ps. 1055), quod accēpisti $\rightarrow$ (kwo.dăk).(ke:).(pis).(ti:) 'that you received' (Pl. Trin. 964). At this stage, iambic shortening, both wordinternal and cross-word, was a phrase-level process, a conclusion which is further corroborated by the necessary synchronic cross-stratal interactions of stress and shortening. ${ }^{7}$ However, the later history of the process (Fortson 2008) displays aspects of the expected life cycle quite clearly. Firstly, linguistically innovative "popular" verse inscriptions from shortly afterwards, but still dating from early Latin, limited iambic shortening to single words of "iambic" (light-heavy) shape, not polysyllables or word groups. This is a strong indication that the relevant aspects of the (rather complex) constraint interaction enforcing iambic shortening at the phrase level had undergone domain narrowing to the word level in the language employed in these inscriptions. ${ }^{8}$ At the next stage, the process remained at the word level, but underwent further prosodic restrictions in situ, e.g. in later republican and imperial verse, shortening was restricted to long vowels only, and not closed syllables. Finally, we see clear evidence in imperial

7 Consequently, Mester (1994) and Prince \& Smolensky (2004) make incorrect predictions with regard to stress placement and shortening in [de.'ko:.re:s] (predicted ['de.ko.re:s]) and [fi.,de:.li.'ta:.tem] (predicted [,fi.de.'li.ta.tem] or [fi.,de.li.'ta..tem]).

8 Notably, the demotion of NonFinAliTy in the word-level grammar (reflecting its position previously in the phrase level) can result in iambic shortening in "iambic" words only, and not longer polysyllables, as it is only in these forms that exhaustive footing is required to create a well-formed foot (not monomoraic) and a well-formed PWd (containing a foot). See Sen (2015a) for details. 
Latin for lexicalization, the final stage of the life cycle. Iambic shortening ceased to be productive, but a handful of shortened forms continued as the standard, lexically stored items in the language, e.g. bene 'well', modo 'only', ego 'I', sibi 'him (dat.)'. Evidence from verse scansion (as well as other indirect sources not discussed here) and the later development of the vowels in question across several centuries have therefore permitted us to reconstruct the life cycle of this process, in line with the predictions of the LCM. Conducting thorough reconstructions in this way will allow us to continue interrogating the LCM's prediction of unidirectionality.

\section{Dialect continua}

Geographical differences can reveal the story of a sound change. Changes may have points of origin from which they spread, with the development often much more advanced in those focal points than in outlying areas. Schuchardt (1885) called this phenomenon "the spatial projection of temporal differences" (translated by Bermúdez-Otero 2015). "Advanced" in this sense may refer to several phenomena: the two aspects relevant to the LCM are rule generalization, and domain narrowing in the life cycle. Language families stemming from a common origin can provide a valuable source of longitudinal evidence, spanning centuries, for testing the LCM's prediction that a change may be seen to progress along the life cycle at different rates in different varieties, as demonstrated by Ramsammy (2015) and Bermúdez-Otero (2015).

For example, as dialectal offshoots of spoken Latin, the Romance languages display numerous similar sound changes. Some languages have advanced versions of a change, displaying one or several of the following traits: it affects (i) larger natural classes of sounds, (ii) in more general environments, and (iii) within smaller morphosyntactic domains. Other Romance languages may display the same change, but with smaller targets and environments, and/or larger morphosyntactic domains. A thorough investigation of the Romance languages with a specific focus on ascertaining phenomena displaying these traits would be a critical addition to the interrogation of the LCM.

A sound change which may be well-suited to this exploration is the /l/-vocalization found in several Romance languages (see Recasens 1996, 2012), including French, Spanish, Portuguese, Provençal, Catalan, and some Italian dialects, e.g. Latin alba 'white' > French aube, where the $<\mathrm{u}>$ spelling reflects $\mathrm{l}>\mathrm{u}$ before a consonant in Old French. As the change began very early in several branches (pre-10th cent. in French) we can hypothesize that it was a single linguistic phenomenon occurring at different rates across early European Romance branches, 
in a dialect continuum. Such a hypothesis is supported by the differences in the contexts for the change across the languages, with French one of the most advanced in terms of where vocalization has occurred, and standard Italian the least (see Recasens 1996). For example, whereas French /l/ vocalized after /a o u/ and before any consonant, Portuguese $\mathrm{l}>\mathrm{u}$ was only after $/ \mathrm{a} /$, and before the consonants / $\mathrm{t} \mathrm{p} \mathrm{s/.} \mathrm{This} \mathrm{gives} \mathrm{us} \mathrm{a} \mathrm{continuum} \mathrm{in} \mathrm{terms} \mathrm{of} \mathrm{the} \mathrm{contexts}$ for applicability of /l/-vocalization (adapted from Manz 2001: see references therein).

\begin{tabular}{llllll}
\hline \hline & Italian & Spanish & Portuguese & French & \\
\hline $\begin{array}{l}\text { Pre- } \\
\text { dental }\end{array}$ & altro & otro & outro & autre & 'other' \\
$\begin{array}{l}\text { Pre- } \\
\text { velar9 }\end{array}$ & dolce & dulce & doce & doux & 'sweet' \\
$\begin{array}{l}\text { Pre- } \\
\text { labial }\end{array}$ & alba & alba & alva & aube & 'dawn' \\
\hline \hline
\end{tabular}

Table 1: Continuum of /l/-vocalization in the Romance languages.

(shaded $=$ vocalized)

This kind of evidence points to the spread of a sound change with conservative-to-innovative dialectal variation underlying the differences that are seen in the Romance languages. Rule generalization is the mechanism in play, whereby the environments in which a process applies are initially restricted (a state-of-affairs maintained in conservative dialects), but gradually become more wide-reaching (as seen in the innovative varieties). Such a geographically and historically broad continuum has parallels, e.g. /s/-palatalization contexts in Germanic dialects, with Oslo Norwegian the most conservative (pretautosyllabic-/l/ only), Northern German in between, and Standard German the most innovative (before several tautosyllabic consonants) (Ramsammy 2015). Recalling the initial stages of the life cycle, phonologization and stabilization, the steps involved in rule generalization presumably reflect the scalar phonetic (dis)favourability of the factors involved in the actuation of the change, e.g. rates of phrase-level word-final nasal velarization in Caraqueño Spanish reflect the favourability of the phonetic context: _ Dor »_Lab »_Cor (Ramsammy 2015).

However, little research aside from Ramsammy (2015) and Bermúdez-Otero (2015) has been conducted to ascertain whether the

\footnotetext{
${ }^{9}$ Original velar before palatalization, that is.
} 
same process has undergone a greater degree of domain narrowing in innovative dialects of a language. For example, is there evidence of phrase-level /l/-vocalization in the conservative Romance varieties contemporaneous with evidence for word- or stem-level vocalization in the more innovative ones? With regard to the same process, the authors above note (and illustrate with Swiss German) that the model further predicts that an older, tightly constrained version of the rule may have risen to a higher stratum, while the newer, more general version may occur at a lower level; at the same time, a more conservative dialect may provide contemporaneous evidence for the constrained version only at a lower level, while the general version is not yet in evidence. As a concrete illustration, we need to examine whether there is evidence for stem-level /l/-vocalization in French before dentals (the oldest rule), and at the same chronological stage phrase-level /l/-vocalization in French before labials (i.e. before a labial-consonant-initial word), but also phrase-level /l/-vocalization in Spanish before dentals (the oldest rule at the lowest phonological level in a conservative variety).

Preliminary examinations indicate that Old French may display traces of the life cycle, but a great deal more work needs to be conducted both to clarify this picture, ascertain any sensitivity to the place of the following consonant, and investigate indications of the life cycle in the other Romance languages. In early texts, we see orthographic vocalization in pre-consonantal contexts, hence in plurals such as mantel-s > manteaux 'coats', but not in the singular mantel (e.g. chastel but autres in the 13th-century Lancelot du Lac). Later, we see an analogical levelling of the stem to give a back-formed manteau in the singular, where the original /l/ was word-final. An interpretation of this development is a rule generalization from pre-consonantal vocalization $(/ \mathrm{l} / \rightarrow[\mathrm{u}] / \ldots \mathrm{C})$ either to coda vocalization $(/ \mathrm{l} / \rightarrow[\mathrm{u}] /$ in the coda $)$ or to "final" vocalization $(/ \mathrm{l} / \rightarrow[\mathrm{u}] / \ldots$ _ $)$ in a given morphosyntactic domain. If the former, the rule generalization resulted in reference to syllable structure at the word level, as word-final /l/ was only syllabified in the coda if the following word did not begin with a vowel. If it had previously been a phrase-level rule sensitive only to linear segmental sequence (pre-C), domain narrowing would have occurred,10 and there have been innovations both in the life cycle and the structural description of the rule. If the generalization was to "final vocalization", domain narrowing to the stem level would have occurred, as /l/ was

\footnotetext{
10 To ascertain rigorously whether the rule originally applied at the phrase level, we would need to examine the oldest French evidence for traces that word-final /l/ was sensitive to the nature of the following word-initial sound, more likely to vocalize before a consonant than a vowel.
} 
stem-final in both singular and plural forms. In other words, while a learner might interpret sg. mantel, pl. manteaux as evidence for a stem-, word-, or phrase-level vocalization rule applying pre-consonantally (if a phrase-level rule, alternating sg. mantel manteau depending on the following word), she might only interpret sg. manteau, pl. manteaux as resulting either from stem- or word-level vocalization applying in the coda, or from final vocalization at the stem level only. Either option is conducive to an identical or smaller domain of application than previously. Finally, the elimination of morpheme alternation could straightforwardly lead to lexicalization of the vocalized variant of the stem.

To recap, the life-cycle model makes the following prediction: the Romance dialects in which the domain of the process is narrowed earlier are also the dialects in which in the structural description of the process generalized earlier, as both are indications of the "age" of the rule.

As Bermúdez-Otero (2015) notes, "the causes of rule generalization are imperfectly understood". Above, we reported what may be termed "phonetic" rule generalization, whereby a process gradually comes to be phonologized (etc.) environment by environment, or sound by sound, with each new version of the rule starting the life cycle independently at first stage, regardless of the level the more constrained version of the process has reached. However, we also encountered the possibility of within-level rule generalization, recognized in the analyses of Old High German consonant shift and nasal velarization in Caraqueño Spanish. What conditions whether a generalized version of a rule comes about in situ (i.e. the level of the more constrained version), or whether it must start at the beginning of its life cycle? One scenario is where a new version of the rule is stabilized at the phrase level, but the old version has not yet undergone domain narrowing to the word level. Presumably this is what has occurred in Caraqueño Spanish, where generalization of nasal velarization appears to be at the phrase level. In this case, the rule does indeed start at the beginning of the cycle, but we have only been able to record data from when both new and old versions have stabilized. As discussed by Bermúdez-Otero (2015), "phonetic" rule generalization predicts that a new version should start again from phonologization and stabilization.

However, a generalization may also be "analogical" in nature, where learners apply the rule to a wider natural class of inputs or environments simply through considerations of phonological (or morphological) similarity, with no regard for a phonetic basis, beyond the fact that natural classes are natural. This would be the most obvious 
interpretation of vocalic epenthesis in stop $+/$ l/ in Latin (Sen 2015b), which appears to have spread from $/ \mathrm{bl} /$ to $/ \mathrm{kl} /$, and is found later in $/ \mathrm{pl} /$, an unusual path given that consonant place is altered in the middle member of the spread, as well as voice. The development can be explained by a morphological analogy from /bl/ to /kl/ ("mediative" suffixes began with these sequences) at the word level, with no phonetic conditioning, but a "phonetic" rule generalization from voiced bilabial / bl/ to voiceless /pl/, which occurred later and displayed traces of phonetic conditioning. Presumably, /pl/-epenthesis began life at the start of the life cycle, and the perception of an intervening vocalic element between bilabial stops and /l/ had a phonetic basis which was more pronounced when the stop was voiced.11

This leads us to question how we can reconstruct whether a generalization was analogical or phonetic. As noted, there are independent motivations for phonetic generalizations to begin the life cycle from phonologization, but no equivalent explanation for analogical ones doing so. Evidence of such behaviour might therefore be interpreted as characteristic of phonetic generalization. It is not altogether clear what is predicted for analogical generalizations; presumably we should see generalization in situ for such spreads. Furthermore, any spread that can independently be seen to have clear phonetic conditioning might be suspected of being "phonetic" and vice versa. In practice, reconstructing the motivation for generalizations is not straightforward. For example, Swiss German /o/-lowering, whose environment spread from pre-/r/ to pre-coronal (except /n l/) behaves as a phonetic generalization according to the LCM: the general /o/lowering entered the grammar at the lowest level and underwent domain narrowing independently of pre-/r/ /o/-lowering (BermúdezOtero 2015, Ramsammy 2015). However, can we independently ascertain a phonetic basis for /o/-lowering before / $\mathrm{t} d$ / and before / $\mathrm{r}$, with the latter being a more favourable environment, but which did not arise before /n l/? The LCM would require us to find just such a conditioning influence, or claim that analogical generalizations (i.e. the elimination of [+sonorant] from the environment of the rule) should also begin at the start of the life cycle, then explain why this should be.

A final step in exploring this line of enquiry would be to discover an explanation for the continuum, testing the predictions of the wave model of sound change, which argues that changes have a geographical centre, from which they spread (Schmidt 1872). The Old High German consonant shift (affrication then spirantization) provides a good

11 Sen (2015b) presents further indications that the two spreads are different in nature (analogical and phonetic), based on sensitivity to word frequency. 
historical example from rule generalization (without domain narrowing), with the most innovative dialects near to the focal point of the change in the south, and the most conservative varieties much further away in the north (Bermúdez-Otero 2015). At first glance, neither geography nor historical movements can explain the vocalization cline French $>$ Portuguese $>$ Spanish $>$ Italian (Manz 2001), begging the question of whether this is indeed a single phenomenon or simply a collection of unrelated developments, caused by the prior common presence of dark /l/ pre-consonantally, as in Latin (see Sen 2015b). Detailed investigation into the socio-political histories of these linguistic communities might shed further light upon this important question.

\section{Morpheme-based learning}

What are the mechanisms in processing and acquisition favouring domain narrowing and not domain broadening? According to Bermúdez-Otero \& Trousdale (2012), the former is expected in the course of normal language transmission across the generations, whereas the latter may occur in unique situations such as when largescale adult borrowing results in higher rates of "replication error", i.e. mis-internalizing an encountered phonological rule. They cite the example of stem-level New York City short-/æ/ tensing borrowed into New Orleans English as a word-level process (based on the migration of NYC bankers and merchants to New Orleans). The LCM relies upon the mechanisms used by the infant in normal acquisition to predict unidirectionality; notably the infant must commit unrecoverable errors (unlike recoverable, later-corrected ones, e.g. consonant harmony) based on the morpheme-based analysis of alternations. Bermúdez-Otero (2015) states that "properties derived in a module or submodule are often misanalysed as being already present in its input, leading to the restructuring of input representations... It is thus recurrent input restructuring, firmly rooted in mechanisms of grammar transmission, that imparts its direction to the life cycle of phonological processes".

To interrogate this view, can we reconstruct scenarios whereby mis-internalization can be expected to occur in morpheme-based infant acquisition? Furthermore, what generalizations might infants feasibly draw which are not solely morpheme-based, but rather "gross", frequency-based phonotactic patterns, which may lead to domain broadening as much as narrowing? Given the range of possible generalizations an infant could draw, is it true that the ones selected are always the ones which lead to domain narrowing (or no change)? As an 
example, consider the following output of a stem-level final devoicing rule:

(14) SL dada dad-a dad a dad $\rightarrow$ dada dat-a dat a dat

When the infant learner encounters such a string, she may logically mis-analyze the data to be the result of a non-word-initial devoicing rule based on the frequency of occurrence of individual sounds: three out of four non-initial coronal stops in the string are voiceless. This might be described as learning based on gross phonotactic patterns. The result of such a generalization would be domain broadening, alongside rule generalization (final > non-initial), as the resulting devoicing rule would be at the word level, hence monomorphemic /dada/ $\rightarrow$ [data]. Why such developments apparently do not occur in the normal course of language acquisition and language change seems to be based on how children learn phonology, since it is precisely the phonotactically constrained patterns seen in child-language production that are later amended to attain adult-like proficiency, e.g. consonant harmony and other processes discussed by Foulkes \& Vihman (2015). If the learner encountered [dada] in the input, she would have reason to reject the hypothesized phonotactic constraint against internal [d], however frequently it otherwise appeared to apply. In the isolated cases of domain broadening, it is precisely such a generalization that has come to apply as a result of adult language contact: New Orleans English speakers have introduced a new word-level constraint *æn on the basis of stem-level NYC evidence such as mann-ing = [mæ:nIn] with a tense vowel, despite NYC evidence from monomorphemic forms without tensing, e.g. Manning = [mænı $]$.

Morphophonological learning, however, is claimed by the LCM to result in non-recoverable mis-analysis, even though it too results in the formation of new phonotactic constraints with counter-evidence in the input. For example, post-nasal /g/-deletion in English is argued to have been raised to the word level on the basis of the overwhelming frequency of word-final pre-consonantal and pausal tokens of each morpheme, as opposed to pre-vocalic (Bermúdez-Otero and Trousdale 2012). This domain narrowing resulted in a new phonotactic constraint at the word level-*ng\#-despite some evidence to the contrary (the pre-vocalic tokens). It must therefore be claimed that the crucial difference between the former and latter scenarios is the involvement of morpheme alternation. Note that neither of the stem morphemes in the hypothetical sentence in (14) alternate according to the devoicing rule: /dada/ is always [dada], and /dad/ is always [dat]. There is no reason for the learner to set up anything other than the accurate UR for 
the former, while the latter is ripe for the final stage of the life cycle, lexicalization as /dat/. Learners therefore draw frequency-based generalizations based on morpheme alternations and restructure their phonotactic constraints accordingly, but if they draw frequency-based generalizations on phonotactic patterns alone, they will recover from these errors once they reach the age where morphophonological learning develops. Testing such a hypothesis is, however, a tricky business; as McCarthy (2005) notes, "Morphophonemic learning is a complex problem" where "the underlying representations influence the grammar and the grammar influences the underlying representations".

Ota (2004) discusses the timescale of phonological learning in the infant, noting that phonotactic knowledge (e.g. distinguishing wellformed from ill-formed segments and sequences) has already developed in children by ten months, whereas productive use of morphology is only fully witnessed from 18 months, before which morphologically complex forms are treated as unanalyzed units; furthermore, the learning of morphophonological alternations may even develop into school age. Ota reports the findings of Jusczyk, Smolensky and Allocco (2002), a study pertinent to the above hypothesis, exploring a scenario whereby phonotactic learning leads to recoverable mis-generalization, which is corrected by later morphemebased learning. The study found that forms showing regressive nasal place assimilation in English were preferred at 4-1/2 to 10 months, based on the adult stem-internal assimilation pattern. However, assimilation was then dispreferred at fifteen months, on the basis of the failure of assimilation across morphemes in the input, e.g. input, pinpoint. If these forms were considered to be unanalyzable monomorphemic units, the learner has counter-evidence to the phonotactic constraint against heterorganic, nasal-C2 sequences, hence "recovers" from the phonotactic generalization. However, when adultlike morphological units are later identified, place assimilation within stems is re-established. The learner has therefore acquired a stem-level rule through the analysis of morphological structure.

Learnability of a grammar from available input has been a concern of the OT literature in particular. Although much of the focus is on learning phonotactic patterns, some research has addressed morphophonological learning (e.g. Ota 2004, McCarthy 2005, Coetzee 2009). ${ }^{12}$ Little work has done so in the context of mis-analyzing the input as a source of language change through domain narrowing, with the exception of Bermúdez-Otero (2003, §6 in particular), who considers the problem through the levels in Stratal OT. He interprets

\footnotetext{
12 I thank Mits Ota for these references and for email discussion on the topic.
} 
the error-proneness of the learner's purported procedure for assigning input representations to alternating items as one of the model's greatest strengths, as it predicts diachronic analogical change.

To conclude this section, let us consider the type of acquisition evidence that would be useful for a historical phonologist examining unidirectionality within the life cycle. Consider an artificial language study where an infant learner is exposed to the following evidence, as the result of a word-level coda $d \rightarrow r$ lenition rule (word-finally and preconsonantally). ${ }^{13}$

(15) Artificial language evidence to which the learner is exposed

a. There is no word-final [d]

b. There is no phrase-final [d] (a subset of word-final [d])

c. There is stem-final [d], but it alternates between [d] when a vowel-initial suffix follows and [r] when either word-final or a consonant-initial suffix follows

(16) Examples: relevant parts in italics relating to the patterns in (15)

a. dad-a dar-ka dar ker a pir

b. dad-a dar-ka dar ker a pir

c. dad-a dar-ka dar ker a pir

Based on the above patterns (using several stems and affixes in an experimental setting), what grammars would an infant learner at premorphophonological ("pre-morph") and post-morphophonological ("post-morph") learning stages construct?

(17) Does the learner (italics highlight the results of misgeneralizations):

a. Successfully acquire the word-level rule?

I.e. dad-a dar-ka dar ker a pir

b. Generalize the stem-final pattern to words, so introduce an alternation based on following environment across words? This would be domain broadening to the phrase level. I.e. dad-a dar-ka dar ked a pir

\footnotetext{
13 I have used lenition of /d/ to [r] rather than devoicing to [t] to avoid the problem of purported (by no means clear) universal learning constraints in drawing generalizations. A discrimination or acceptability task would be most appropriate to the age groups considered. I thank Robyn Orfitelli for discussion on this point.
} 
c. Generalize the stem-final (word-internal) alternant [d] to words, so treat every stem-final [d r] as [d], eliminating alternation? This would be "rule death".

I.e. dad-a dad-ka dad ked a pid

d. Generalize the word-final pattern to stems, so treat every morpheme-final $[\mathrm{d} r]$ as [r], eliminating alternation? This would be domain narrowing to the stem level.

I.e. dar-a dar-ka dar ker a pir

Presumably a pre-morph learner would successfully acquire the phonotactic constraint against word-final $[\mathrm{d}]\left({ }^{*} \mathrm{~d} \#\right)$, and perhaps even draw the gross phonotactic generalization that non-word-initial [d] is prohibited (only one instance in the above sentence), yielding not only the same effects as domain narrowing ([dar-a]), but also a prohibition on stem-internal [d] (e.g. hypothetical [kara] for /kada/). The resulting non-initial $d \rightarrow r$ rule could therefore be either a stem- or word-level process (prefixed forms might help differentiate). Either way, no domain broadening would occur in this particular example.

A post-morph learner might be sensitive to the relative frequency of morpheme alternants, rather than simply sound patterning. If the coda alternants with $[\mathrm{r}]$ are significantly more common than the pre-vocalic [d]-alternants for a given morpheme, or over the full range of morphemes encountered, the learner might generalize these to the latter context, resulting in stem-level lenition targeting every stem-final /d/ regardless of the following suffix. If, however, pre-vocalic alternants are significantly more common (e.g. the language has many, frequently employed vowel-initial suffixes), the [d]-alternant may be generalized, resulting in rule death: underlying /d/ remains [d] on the surface. Finally (and crucially), when might domain broadening be expected to occur, extending alternation to word-final positions? We might envisage an inflectional language where suffixation of stems is the norm, but where instances of stem-final /d/ surfacing as word-final [r] remain (i.e. zero-suffixed forms). The learner might then encounter the word-internal stem alternation very regularly, providing a motivation for its extension to the word-final context, broadening its domain of application to the phrase level. Aside from the question of how the rule originally came to be at the word level (presumably the language had different morphological patterns at an earlier stage), this scenario would appear to be conducive to domain broadening by a post-morph infant learner.

Ascertaining the circumstances under which domain narrowing, domain broadening, rule death, and accurate transmission are 
predicted by the LCM, through exploring child and adult language learning mechanisms, would therefore provide an invaluable startingpoint for historical phonologists examining the life cycles of sound changes.

\section{Other questions}

The subsections below briefly address the "other questions" identified in (4)-(12) in $\S 2$.

\subsection{Are the phonological levels in synchronic computation innate or acquired?}

This is general issue relating to language acquisition and synchronic phonology, although it also bears upon the question above on morpheme-based learning and the cognitive mechanisms underlying unidirectionality. Bermúdez-Otero (2007) contains some pertinent discussion, acknowledging that the strata can be either innate or emergent. More work in this area is required to explore the mechanisms involved in emergence.

\subsection{How are gradient, phonetic instructions computed and implemented in the "phonetic rule" module?}

This and the following two questions are best studied by laboratorybased phonetic studies into the synchronic effects of a stratal model. Stratal OT has explicitly-formulated elements of storage (UR, stem-level listing) and computation (SL, WL, PL), but no explicit account of phonetic implementation, i.e. mapping phonological categories onto continuous phonetic parameters. Bermúdez-Otero \& Trousdale (2012) suggest that Hamann's (2009) and Boersma's (2009) cue constraints in a bi-directional (perception and production) phonological grammar are a strong candidate to be imported into the LCM to account for listenerbased sound change. We might also consider whether a "phonetic rule" is computed from exemplar memory structured by category-based clouds (Pierrehumbert 2002), even if this information only becomes available at the final stage of the speech production process, with the remainder of the categorical LCM architecture intact.

\subsection{Is rule scattering sufficient to account for phonetics apparently sensitive to morphology or the lexicon?}

Laboratory-based studies into this question have gathered some momentum, with some concluding that rule scattering accounts for the 
phenomena encountered (e.g. Turton 2012, Bermúdez-Otero 2015, Ramsammy 2015), and others arguing that a modular stratal architecture is incapable of modelling some effects (e.g. Sebregts and Strycharczuk 2012). The main challenges to modularity are phonetic effects found to be sensitive to token frequency, neighbourhood density, and contextual probability. Bermúdez-Otero (2007, 2015) suggests that a cascading activation model of speech production (Goldrick and Blumstein 2006) can account for these while maintaining a stratal phonological structure. What precisely such a model can predict with regard to the phenomena hitherto explained by rule scattering remains to be fully investigated.

\subsection{Are there phonetically gradient, lexically gradual sound changes, contrary to the predictions of the life cycle?}

Whether phonological change proceeds by lexical diffusion or regular "neogrammarian" sound change is traditionally one of the main questions in historical phonology, but is not itself immediately relevant to the specific predictions of the LCM, given that both have a place. Regular sound change is a result of a phonetic rule, whereas lexical diffusion reflects the morpheme by morpheme restructuring of underlying representations. However, it predicts that phonetically gradient, but lexically gradual sound changes should not occur, as lexical restructuring can only be categorical. Some studies argue that such types of change do exist (e.g. Bybee 2002, Phillips 2015). Consensus on this issue is yet to be achieved, although it would be difficult for a historical phonological study based on written forms of language to contribute to the debate, given the difficulty of establishing gradience, as discussed in $\S 3$.

\subsection{Do lexically diffusing changes reflect lexically varied phonological computation rather than varied lexical storage?}

This is an interesting question. If domain narrowing (e.g. in post-nasal /g/-deletion in English) occurs through morpheme-based learning (e.g. greater frequency of the [sin] alternant of /sing/), what prevents a rule from narrowing to the word level for one morpheme (delete word-final /g/ in /sing/), but not in another morpheme whose alternants are roughly equally frequent (e.g. it collocates with both vowel- and consonant-initial words equally)? It may be that the infant learner considers all morphemes displaying the particular alternation, and misgeneralizes to give domain narrowing only if the overall frequency of one alternant type is significantly greater than the frequency of the 
other. This hypothesis requires further exploration, through synchronic, historical, and acquisitional studies.

\subsection{What is the full range of predictions of the non-analytic listing of stem-level outputs and are these borne out?}

This question focuses on the synchronic outcomes of a specific claim of Stratal OT found in Bermúdez-Otero \& McMahon (2006). It may be that there are diachronic predictions that can be tested, but the issue is left aside here.

\subsection{What are the factors conditioning the duration of a change's life cycle, and whether it is seen through to lexicalization?}

This is germane to the historical questions raised here, and may be answered through the examination of cognitive mechanisms involved in morpheme-based learning. There are some arguments and reports of pertinent computational studies in Bermúdez-Otero (2015).

\subsection{How does domain narrowing interact with different types of rule generalization, either by natural class or by prosodic span, which can extend the application of a rule within a given level?}

This addresses the key diachronic question of how rule generalization works, and is touched upon above in both $\S 4$ and $\S 5$ (although generalization according to prosodic span was not addressed, e.g. syllable-based to foot-based). Although a detailed study of this topic is itself tangential to the prediction of diachronic unidirectionality, what shape rule generalizations can take, and how "phonetic analogy" (Schuchardt 1885) must be constrained are key questions in examining the histories of individual sound changes (some thoughts in Ramsammy 2015).

6.9 How can the morphosyntactic cycle interact with the computation of prosodic structure in conditioning sound change?

Finally, a historical phonologist might consider the tricky question of how different morphosyntactic effects in sound change can be uncovered, and whether they interact in a constrained fashion. Two types of morphosyntactic conditioning can be discerned (BermúdezOtero and Luís 2009): directly through the cycle, or indirectly via prosodic structure, which is sensitive to morphosyntax (e.g. syllable 
boundaries may coincide with morpheme boundaries). Aside from the separate trajectories of prosody and the cycle, are there any more closely bound interactions? For example, if a rule ceases to apply across word boundaries, how do we know whether this is because it has narrowed from the phrase to the word level, or because the prosodic domain in its structural description has shrunk from the phonological phrase to the prosodic word? In fact, if the latter occurs, it may well trigger the former given the absence of appropriate phrase-level input. Sen (2015a) notes the dual morphosyntactic conditioning in Latin iambic shortening, noting that it was originally sensitive to phonological phrase structure, but naturally ceased to be so once it was restricted to within words.

\section{Conclusion}

The above discussions have addressed several aspects of the life-cycle model, which remains comparatively under-studied given how important and pervasive the life cycle is purported to be. The focus has been on how a historical phonologist examining the sources of evidence commonly available for non-current forms of language might test the diachronic predictions of the LCM. In addition, we have considered how acquisition studies may inform those diachronic predictions, particular in relation to domain broadening. The results of these investigations would also inform synchronic phonological theory, notably into opacity effects and the claims of modularity. Large-scale, long-term diachronic studies need to be undertaken to resolve these pressing questions in historical phonology.

\section{Comments invited}

PiHPh relies on post-publication review of the papers that it publishes. If you have any comments on this piece, please add them to its comments site. You are encouraged to consult this site after reading the paper, as there may be comments from other readers there, and replies from the author. This paper's site is here:

http://dx.doi.org/10.2218/pihph.1.2016.1691

\section{Acknowledgments}

Much of this paper arose from engaging discussion with colleagues in several arenas. The greatest thanks, and a massive intellectual debt, must go to Ricardo Bermúdez-Otero for his generosity in exploring several of these questions with me, particularly during the $24^{\text {th }}$ 
Manchester Phonology Meeting in May 2016. There are far too many places in this paper to report his influence, aside from his published work. The participants (Patrick Honeybone, Mits Ota, Pavel Iosad, Steve Rapaport) of the satellite workshop on the life cycle before the AMC Symposium on Historical Dialectology, University of Edinburgh, June 2016 provided particularly important critical discussion to narrow down the types of historical evidence required. I thank them all for making this hastily organised event a success. Aditi Lahiri has continued to provide invaluable advice on many aspects of theoretical historical research, and Ian Watson has been generous with his advice on Old French phonology. Finally, I thank the participants of the Second Edinburgh Symposium in Historical Phonology, December 2015, for their questions and suggestions following my papers, notably the ideas on the life cycle. All errors, misunderstandings, and misrepresentations remain my own.

\section{Author contact details}

Dr Ranjan Sen

School of English, University of Sheffield

Jessop West, 1 Upper Hanover Street

Sheffield S3 7RA

United Kingdom

ranjan.sen@sheffield.ac.uk

\section{References}

Baldi, Philip. 1994. Some thoughts on Latin rhotacism. General Linguistics. 34. 209-216.

Bermúdez-Otero, Ricardo. 2003. The acquisition of phonological opacity. In Jennifer Spenader, Anders Eriksson \& Östen Dahl (eds.), Proceedings of the Stockholm workshop on 'Variation within Optimality Theory', 25-36. Stockholm: Department of Linguistics, University of Stockholm.

Bermúdez-Otero, Ricardo. 2007. Diachronic phonology. In Paul V. de Lacy (ed.), The Cambridge handbook of phonology, 497-517. Cambridge; New York: Cambridge University Press.

Bermúdez-Otero, Ricardo. 2015. Amphichronic explanation and the life cycle of phonological processes. In Patrick Honeybone \& Joseph C. Salmons (eds.), The Oxford handbook of historical phonology, 374399. Oxford: Oxford University Press.

Bermúdez-Otero, Ricardo \& Ana R. Luís. 2009. Cyclic domains and prosodic spans in the phonology of European Portuguese functional 
morphs. Paper presented at the 6th Old World Conference in Phonology (OCP), Edinburgh, 24 January 2009.

Bermúdez-Otero, Ricardo \& April McMahon. 2006. English phonology and morphology. In Bas Aarts \& April McMahon (eds.), The handbook of English linguistics, 382-410. Malden, MA.: Blackwell.

Bermúdez-Otero, Ricardo \& Graeme Trousdale. 2012. Cycles and continua: On unidirectionality and gradualness in language change. In Terttu Nevalainen \& Elizabeth C. Traugott (eds.), The Oxford handbook of the history of English, 691-720. Oxford: Oxford University Press.

Blevins, Juliette. 2004. Evolutionary phonology: The emergence of sound patterns. Cambridge: Cambridge University Press.

Boersma, Paul. 2009. Cue constraints and their interaction in phonological perception and production. In Paul Boersma \& Silke Hamann (eds.), Phonology in perception, 55-109. Berlin: Mouton de Gruyter.

Bybee, Joan. 2002. Word frequency and context of use in the lexical diffusion of phonetically conditioned sound change. Language Variation and Change 14. 261-290.

Coetzee, Andries W. 2009. Learning lexical indexation. Phonology 26(1). 109-145.

Eckert, Penelope \& Sally McConnell-Ginet. 1992. Communities of practice: Where language, gender and power all live. In Kira Hall, Mary Buchholtz \& Birch Moonwomon (eds.), Locating power: Proceedings of the Second Berkeley Women and Language Conference, 89-99. Berkeley: Berkeley Women and Language Group, University of California.

Ellis, Lucy \& William J. Hardcastle. 2002. Categorical and gradient properties of assimilation in alveolar to velar sequences: Evidence from EPG and EMA data. Journal of Phonetics 30. 373-396.

Fortson, Benjamin W., IV. 2008. Language and rhythm in Plautus: Synchronic and diachronic studies. Berlin; New York: Walter de Gruyter.

Foulkes, Paul \& Marilyn Vihman. 2015. First language acquisition and phonological change. In Patrick Honeybone \& Joseph C. Salmons (eds.), The Oxford handbook of historical phonology, 289-312. Oxford: Oxford University Press.

Glare, P. G. W. (ed.). 1996. Oxford Latin Dictionary (2nd edn.). Oxford: Clarendon Press.

Goldrick, Matthew \& Sheila E. Blumstein. 2006. Cascading activation from phonological planning to articulatory processes: Evidence from tongue twisters. Language and Cognitive Processes 21(6). 649-683. 
Hamann, Silke. 2009. The learner of a perception grammar as a source of sound change. In Paul Boersma \& Silke Hamann (eds.), Phonology in perception, 111-149. Berlin: Mouton de Gruyter.

Jacobs, Haike. 2003. The emergence of quantity-sensitivity in Latin: Secondary stress, iambic shortening, and theoretical implications for "mixed" stress systems. In Eric Holt (ed.), Optimality theory and language change, 229-247. Dordrecht; Boston; London: Kluwer.

Jun, Jongho. 2004. Place assimilation. In Bruce Hayes, Robert M. Kirchner \& Donca Steriade (eds.), Phonetically based phonology, 58-86. Cambridge: Cambridge University Press.

Jusczyk, Peter, Paul Smolensky \& Theresa Allocco. 2002. How Englishlearning infants respond to markedness and faithfulness constraints. Language Acquisition 10. 31-74.

Lahiri, Aditi, Tomas Riad \& Haike Jacobs. 1999. Diachronic prosody. In Harry van der Hulst (ed.), Word prosodic systems in the languages of Europe, 335-422. Berlin, New York: Mouton de Gruyter.

Manz, Kathryn. 2001. The effacement and vocalization of preconsonantal 1 in Old French. Haverford College, Swarthmore: BA dissertation.

McCarthy, John J. 2002. Comparative markedness (long version). Ms., University of Massachusetts, Amherst.

McCarthy, John J. 2005. Taking a free ride in morphophonemic learning. Catalan Journal of Linguistics 4. 19-55.

Mester, R. A. 1994. The quantitative trochee in Latin. Natural Language and Linguistic Theory 12.1-61.

Ota, Mitsuhiko. 2004. The learnability of the stratified phonological lexicon. Journal of Japanese Linguistics 20. 19-40.

Phillips, Betty S. 2015. Lexical diffusion in historical phonology. In Patrick Honeybone \& Joseph C. Salmons (eds.), The Oxford handbook of historical phonology, 359-373. Oxford: Oxford University Press.

Pierrehumbert, Janet. 2002. Word-specific phonetics. In Carlos Gussenhoven \& Natasha Warner (eds.), Laboratory phonology 7, 101-139. Berlin: Mouton de Gruyter.

Prince, Alan \& Paul Smolensky. 2004. Optimality theory: Constraint interaction in generative grammar. Malden, MA.; Oxford: Blackwell.

Ramsammy, Michael. 2015. The life cycle of phonological processes: Accounting for dialectal microtypologies. Language and Linguistics Compass 9(1). 33-54.

Recasens, Daniel. 1996. An articulatory-perceptual account of vocalization and elision of dark $/ \mathrm{l} /$ in the Romance languages. Language and Speech 39(1). 63-89. 
Recasens, Daniel. 2012. A phonetic interpretation of the sound changes affecting dark /l/ in Romance. In Maria-Josep Solé \& Daniel Recasens (eds.), The initiation of sound change: Perception, production, and social factors, 57-76. Amsterdam: John Benjamins.

Roberts, Philip J. 2012. Latin rhotacism: A case study in the life cycle of phonological processes. Transactions of the Philological Society 110(1). 80-93.

Schmidt, Johannes. 1872. Die verwandtschaftsverhältnisse der indogermanischen sprachen. Weimar: H. Böhlau.

Schuchardt, Hugo. 1885. Über die lautgesetze: Gegen die junggrammatiker. Berlin: Oppenheim.

Sebregts, Koen \& Patrycja Strycharczuk. 2012. Phonetically gradient allomorphy: The case of the Dutch past tense. Paper presented at the 20th Manchester Phonology Meeting (mfm), 24 May 2012.

Sen, Ranjan. 2015a. Pre-classical prevarication in Latin feet: Stratal synchronic structure and discretionary diachronic development. Paper presented at the 12th Old World Conference in Phonology (OCP), Barcelona, 27-30 January 2015.

Sen, Ranjan. 2015b. Syllable and segment in Latin. Oxford: Oxford University Press.

Serbat, Guy. 1975. Les dérivés nominaux latins à suffixe médiatif. Paris: Les Belles Lettres.

Strycharczuk, Patrycja. 2012. Phonetics-phonology interactions in presonorant voicing. University of Manchester: PhD dissertation.

Turton, Danielle. 2012. The darkening of English /l/: A stochastic stratal OT analysis. Unpublished ms., University of Manchester, URL http://ling.auf.net/lingBuzz/001524.

Vaux, Bert. 2008. Why the phonological component must be serial and rule-based. In Bert Vaux \& Andrew Nevins (eds.), Rules, constraints, and phonological phenomena, 20-60. Oxford: Oxford University Press. 